\title{
Variability of Polygalacturonase and Protein Isoelectric Focusing Patterns in Botrytis cinerea Isolates
}

\author{
By P. MAGRO, ${ }^{1 *}$ P. DI LENNA, ${ }^{1}$ P. MARCIANO ${ }^{1}$ AND C. PALLAVICINI ${ }^{2}$ \\ 1 Istituto di Patologia Vegetale, Università di Padova, Via Gradenigo 6, 35100 Padova, Italy \\ 2 Istituto di Chimica e Industrie Agrarie, Università di Padova, Via Gradenigo 6, \\ 35100 Padova, Italy
}

(Received 7 December 1979; revised 28 February 1980)

\begin{abstract}
Acetone precipitates from culture filtrates of three isolates of Botrytis cinerea were resolved by isoelectric focusing on polyacrylamide gels to detect differences in the polygalacturonase and protein patterns. Only a few bands - four in the protein patterns and two in the polygalacturonase patterns - were common to all the isolates. Differences were also detected in polygalacturonase and protein patterns of the same isolate at different ages of culture $(7,14$ and $21 \mathrm{~d}$ ). Identical polygalacturonase patterns were obtained when isoelectric focusing was applied to an acetone precipitate either directly or after further purification by ion-exchange chromatography.
\end{abstract}

\section{INTRODUCTION}

Recently, polygalacturonase (PG) isoenzymes of Botrytis cinerea Pers. ex Fr. have been described by Zalewska-Sobczak \& Urbanek (1975) for B. cinerea E-200 and by Drawert \& Krefft (1978) for $B$. cinerea CBS 144.55 using, respectively, ion-exchange chromatography and isoelectric focusing as resolution techniques. However, the number of isoenzymes found was different: the former isolated only two PG peaks (PG1 and PG2) whereas the latter isolated four isoenzyme bands in the region of $\mathrm{pI} \mathrm{4.} \mathrm{These} \mathrm{results} \mathrm{suggest} \mathrm{either} \mathrm{that} \mathrm{the}$ isoenzyme pattern of extracellular PG is not a characteristic of the species but differs from one isolate to another, or that different purification techniques may have led to different results. We therefore decided to check both hypotheses experimentally.

Acetone precipitates from culture filtrates of three isolates of $B$. cinerea were resolved by isoelectric focusing on polyacrylamide gels (i) to detect any differences in the isoenzyme and protein patterns, (ii) to determine whether these patterns vary with the age of cultures and (iii) to determine whether the isoenzyme patterns of PG obtained by focusing the crude extract differed from those resulting after a further purification step by ion-exchange chromatography.

\section{METHODS}

Isolates. Shoots showing infection by $B$. cinerea were collected from Venetum (N.E. Italy) vineyards and some 30 single-spore isolates were obtained. Each isolate was cultured on potato-dextrose agar (PDA) and stored under liquid paraffin at $15^{\circ} \mathrm{C}$. From among these isolates, stored in our Institute collection, three (designated $\mathrm{H}, \mathrm{BB}$ and $\mathrm{PP}$ ) were chosen at random and used for the present study.

Enzyme preparation. The isolates were surface cultured in Czapek's liquid medium (pH 5) containing $1 \%$ $(w / v)$ citrus pectin as sole carbon source and thiamin $\left(0.1 \mu \mathrm{g} \mathrm{ml}^{-1}\right)$. The inoculum was one agar disc $(3 \mathrm{~mm}$ diam.) cut from the edge of a $3 \mathrm{~d}$ non-sporulating culture on PDA inoculated from the original cultures under liquid paraffin. The mycelium was grown at $20^{\circ} \mathrm{C}$ in $250 \mathrm{ml}$ Erlenmeyer fiasks containing $50 \mathrm{ml}$ medium. Culture media were collected and precipitated with cold acetone between 20 and $66 \%(v / v)$ as reported by Zalewska-Sobczak \& Urbanek (1975). Acetone precipitates from 7, 14 and $21 \mathrm{~d}$ cultures of isolate $\mathrm{H}$ were 
used to test the effect of age on PG patterns, and the three isolates were compared using samples from $14 \mathrm{~d}$ cultures. Before isoelectric focusing, samples were exhaustively dialysed against distilled water for $24 \mathrm{~h}$ at $4^{\circ} \mathrm{C}$. Before ion-exchange chromatography on DEAE-cellulose, samples were equilibrated against $10 \mathrm{~mm}$ sodium phosphate buffer ( $\mathrm{pH} \mathrm{6.4)}$ for $12 \mathrm{~h}$ at $4{ }^{\circ} \mathrm{C}$. Protein was determined by the method of Lowry.

Isoelectric focusing on polyacrylamide gels. Isoelectric focusing in $7.5 \%(\mathrm{v} / \mathrm{v})$ polyacrylamide gels $(8 \mathrm{~cm}$ long) was carried out as described by Wringley (1971) with $2.5 \%$ (v/v) of carrier ampholite pH 3.5 to 10 (LKB). Focusing was performed for $5 \mathrm{~h}$ at $4^{\circ} \mathrm{C}$, using a commercial apparatus (Bio-Rad), by applying $1.0 \mathrm{~mA}$ per gel and gradually raising the voltage to $200 \mathrm{~V}$. This voltage was maintained until the end of the run. Standard samples, containing about $200 \mu \mathrm{g}$ protein and $10 \%(\mathrm{w} / \mathrm{v})$ sucrose, were layered on to the top of the gels (anode). The cathode solution was $0.4 \%(\mathrm{v} / \mathrm{v}) 2$-aminoethanol and the anode solution $0.2 \%$ (v/v) sulphuric acid.

For protein identification, gels were washed in $10 \%(w / v)$ trichloroacetic acid and stained for $1 \mathrm{~h}$ with $0.0625 \%(\mathrm{w} / \mathrm{v})$ Coomassie Blue R 250 in $20 \%$ (w/v) trichloroacetic acid as described by Wright et al. (1973). Excess stain was removed by repeated washing with $12.5 \%(w / v)$ trichloroacetic acid.

PG isoenzyme identification was carried out as reported by Lisker \& Retig (1974). For staining, gels were generally incubated for $30 \mathrm{~min}$ with $1.2 \%$ (w/v) polygalacturonic acid (Sigma, grade III), washed with tap water and immersed for 4 to $5 \mathrm{~min}$ in $0.05 \%$ Ruthenium Red solution. Longer incubation times were sometimes needed to enhance the staining of some bands. The $\mathrm{pH}$ gradient was determined by cutting gels (without samples) into $10 \mathrm{~mm}$ slices. The slices were soaked in $2 \mathrm{ml}$ distilled water for $2 \mathrm{~h}$ and the $\mathrm{pH}$ was measured at $22^{\circ} \mathrm{C}$ using a pH meter equipped with a microelectrode. Controls included gels incubated in substrate-deficient medium and heat-treated gels $\left(100^{\circ} \mathrm{C}\right.$ for $\left.5 \mathrm{~min}\right)$.

lon-exchange chromatography. Ion-exchange chromatography was performed on extracts from isolate $\mathrm{PP}$, since this had the simplest PG pattern. It was carried out on a refrigerated $\left(4{ }^{\circ} \mathrm{C}\right) 1.6 \times 30 \mathrm{~cm}$ DEAEcellulose column equilibrated with 10 mM-sodium phosphate buffer (pH 6.4) followed by $400 \mathrm{ml}$ of a linear 0 to $0.7 \mathrm{M}-\mathrm{NaCl}$ gradient in the same buffer. The flow rate was $0.5 \mathrm{ml} \mathrm{min}-1$ and $4.5 \mathrm{ml}$ fractions were collected for protein and PG activity determinations. Protein content was determined by recording the absorbance at $280 \mathrm{~nm}$. PG activity was tested by the procedure of Nelson (1944) with D-galacturonic acid as standard. The reaction mixtures, containing $4 \mathrm{ml} 0.5 \%(\mathrm{w} / \mathrm{v})$ polygalacturonic acid in $0.1 \mathrm{M}$-sodium acetate buffer (pH 5) and $0.1 \mathrm{ml}$ enzyme fraction, were incubated for suitable periods at $30^{\circ} \mathrm{C}$. Reaction mixtures containing boiled enzyme, or lacking substrate, were used as controls. Activity is expressed as units contained in each fraction. A unit is defined as the amount of enzyme which liberated $1 \mu \mathrm{mol}$ galacturonate equivalent in $1 \mathrm{~min}$ under the condition of assay. Active fractions were pooled and subjected to isoelectric focusing.

\section{RESULTS}

Figure 1 shows the isoenzyme patterns of $P G$ secreted by isolate $H$ at different ages of culture $(7,14$ and $21 \mathrm{~d})$. At the first harvest, seven isoenzyme bands were detected; at the second and third, 16 bands were detected, with no differences in pI values for comparable bands. The only difference between 14 and $21 \mathrm{~d}$ cultures was in the staining intensity of some bands.

Protein patterns of the same isolate $\mathbf{H}$ at the same ages of culture are shown in Fig. 2. The protein bands showed variability both in number and in $\mathrm{pI}$ values. The greatest number of bands was detected in $14 \mathrm{~d}$ cultures, the least at $21 \mathrm{~d}$. Throughout the whole experimental period only one band (pI 5.7) was consistently present.

When the isolates were compared using $14 \mathrm{~d}$ cultures (Fig. 3), they exhibited PG patterns with bands differing in number and in $\mathrm{pI}$ values, with the exception of those at $\mathrm{pI} 4 \cdot 2$ and 4.5 which were present in all isolates. The three isolates also showed marked differences in their protein patterns (Fig. 4): they exhibited only four common bands at pI 4.2, 7.0, 7.2 and $7 \cdot 5$.

Acetone precipitate from isolate PP (14 d cultures), subjected to ion-exchange chromatography, showed two peaks (A and B) of PG activity (Fig. 5). The A peak was bound to the resin and eluted with the $\mathrm{NaCl}$ gradient. When separately subjected to isoelectric focusing, the $A$ and $B$ forms were each resolved into two isoenzyme bands (Fig. 6). Together these accounted for the bands obtained by focusing the original acetone precipitate (Fig. 3 ). 


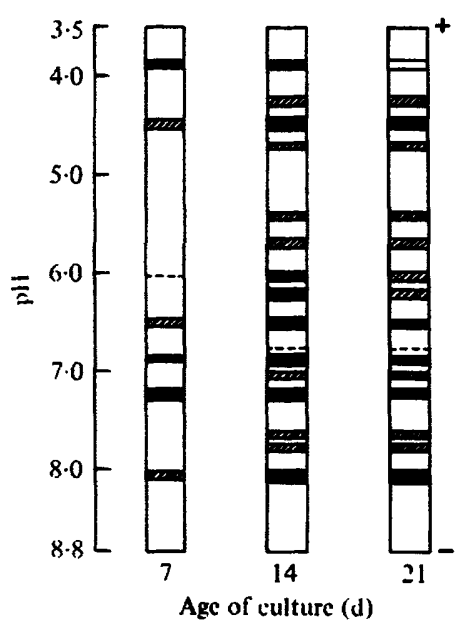

Fig. 1

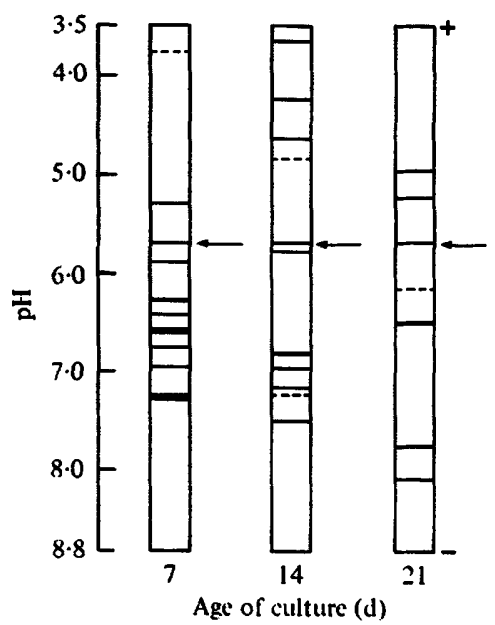

Fig. 2

Fig. 1. PG patterns after isoelectric focusing on polyacrylamide gels of $B$. cinerea isolate $H$ at 7 , 14 and $21 \mathrm{~d}$ of culture. Intensity of PG staining: $\square$ high; $\square$ medium; $\square$, low; - - - , trace.

Fig. 2. Protein patterns after isoelectric focusing on polyacrylamide gels of $B$. cinerea isolate $\mathbf{H}$ at 7,14 and $21 \mathrm{~d}$ of culture. Arrows indicate the bands common to all three patterns (----, only trace).

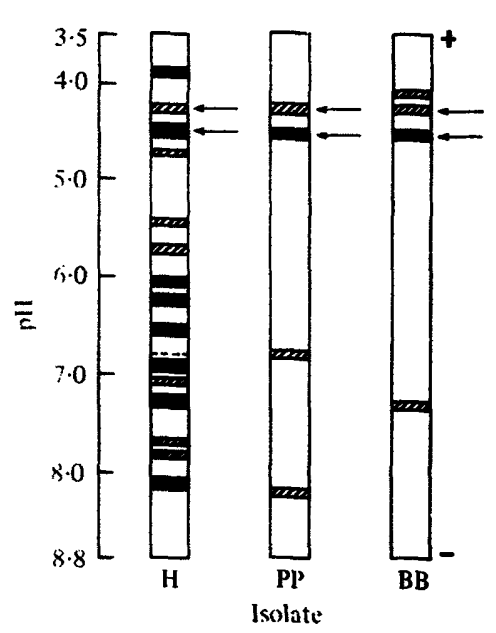

Fig. 3
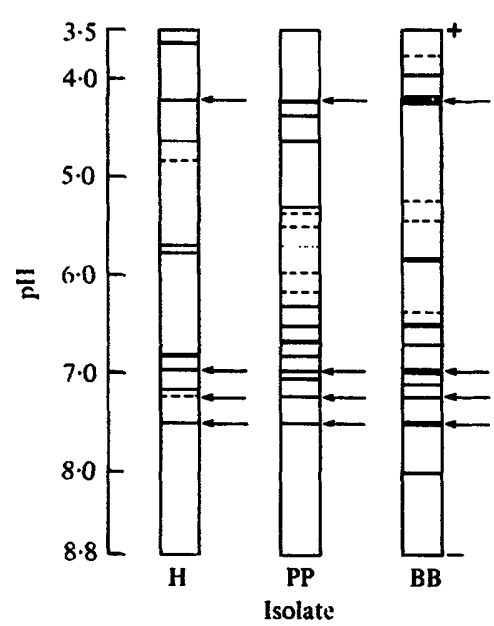

Fig. 4

Fig. 3. PG patterns after isoelectric focusing on polyacrylamide gels of $B$. cinerea isolates $H, P P$ and $B B$ at $14 \mathrm{~d}$ of culture. Intensity of PG staining: trace. Arrows indicate the bands common to all three patterns.

Fig. 4. Protein patterns after isoelectric focusing on polyacrylamide gels of $B$. cinerea isolates $H$, PP and BB at $14 \mathrm{~d}$ of culture. Arrows indicate the bands common to all three patterns (----, only trace).

\section{DISCUSSION}

Isolates $\mathrm{H}, \mathrm{PP}$ and $\mathrm{BB}$ secrete several proteins into the culture medium, as found by Drawert \& Krefft (1978) with $B$. cinerea CBS 144.55. When subjected to isoelectric focusing, these proteins were resolved into several bands widely distributed between pI 3.7 and 8.0 and not confined to the acid zone of the gels as reported for $B$. cinerea CBS 144.55. Moreover, the proteins from different isolates differed in number, $\mathrm{pI}$ and intensity of staining. 


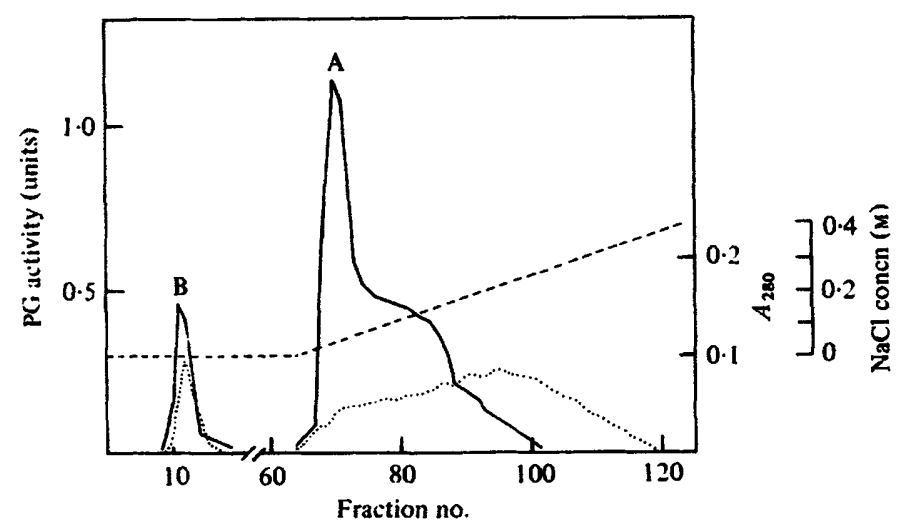

Fig. 5. Elution profile of PG activity by ion-exchange chromatography of $B$. cinerea isolate PP: $\longrightarrow$ PG activity; $\cdots \cdots, A_{280} ;-\cdots, \mathrm{NaCl}$ concentration.

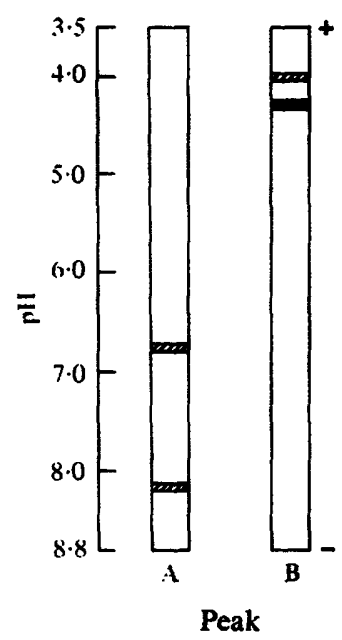

Fig. 6. PG patterns after isoelectric focusing on polyacrylamide gels of the peaks of activity (A and B, see Fig. 5) from ion-exchange chromatography of $B$. cinerea isolate PP. Intensity of PG staining: , high; $\mathbb{Z}$, medium.

At different culture ages, marked qualitative and quantitative changes in protein patterns also occurred in the isolates examined.

Reports of differences in protein patterns among different isolates of the same species are few, in part contradictory and usually obtained in attempts to use protein patterns as a taxonomic key for recognizing different species. Chang et al. (1962) found that a wild strain as well as a mutant strain of Neurospora crassa had distinctive protein patterns. Different conclusions were reached by Clare (1963) who stated that isolates of the same Pythium species from different localities were either indistinguishable or showed little difference. $\mathrm{He}$ further showed that filtrates of any one isolate harvested at three different ages showed identical electrophoretic patterns characteristic of each Pythium species.

Whitney et al. (1968), working with Verticillium dahliae, Fusarium oxysporum and Verticillium albo-atrum, found few intraspecific differences in protein patterns of two isolates of $V$. albo-atrum. Their results, however, showed that marked changes in protein bands of the three species occurred in the culture period examined. In more recent work, Chesson et al. (1978) found that one strain of Cephalosporium diospyri gave essentially the same soluble protein patterns during a culture period of $11 \mathrm{~d}$. 
That heterokaryosis in $B$. cinerea causes a high degree of natural phenotypic variability is well established (cf. Grindle, 1979) but our results also suggest that between random isolates of the fungus there exists variability in physiological features such as protein as well as enzyme patterns. Our results indicate that different isolates have PG patterns which differ one from another both in the number and in the $\mathrm{pI}$ values of the isoenzymes. The multiple forms of PG obtained from the $B$. cinerea isolate studied by Drawert \& Krefft (1978) were

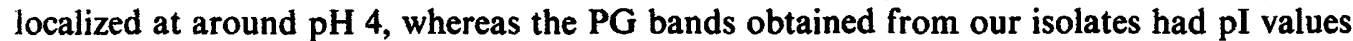
not only near 4 but also at other values.

Multiple enzyme forms could be the results of the evolution from simple enzymic patterns of an ancestor in response to changing hosts or habitat (Willetts et al., 1977). From this point of view, more PG forms would indicate more opportunities for inducing disease on different hosts. Our results are therefore consistent with the well-known ability of $B$. cinerea to infect a wide host range.

In isolate $H$, the PG pattern was more constant with increasing culture age than was the soluble protein pattern. Between 14 and $21 \mathrm{~d}$ cultures there was a complete change in the protein pattern while in the PG pattern the only difference was in the staining intensity.

In conclusion, our results suggest that attempts to evaluate the qualitative and quantitative ability of $B$. cinerea to produce pectic enzymes must take into account the heterogeneity of the species and that comparisons between isolates must be made at the same age of culture and with the same resolution techniques.

The authors would like to thank Dr R. J. W. Byrde and Mr A. H. Fielding, Long Ashton Research Station, University of Bristol, for helpful discussion of the manuscript.

\section{REFERENCES}

Chang, L. O., Srb, A. M. \& Steward, F. C. (1962). Electrophoretic separations of the soluble proteins of Neurospora. Nature, London 193, 756-759.

Chesson, A., Morgan, J. J. \& Codner, R. C. (1978). Comparative electrophoretic study of proteins of Acremonium-like hyphomycetes. Transactions of the British Mycological Society 70, 345361.

Clare, B. C. (1963). Starch-gel electrophoresis of protein as an aid in identifying fungi. Nature, London 200, 803-804.

Drawert, F. \& KrefFt, M. (1978). Charakterisierung extrazellularer Proteine und Enzyme aus Pektinkulturfiltraten von Botrytis cinerea. Phytochemistry 17, 887-890.

GRINDLE, M. (1979). Phenotypic differences between natural and induced variants of Botrytis cinerea. Journal of General Microbiology 111, 109-120.

LISKER, N. \& RETIG, N. (1974). Detection of polygalacturonase and pectin lyase isoenzymes in polyacrylamide gels. Journal of Chromatography 96, 245-249.

NELSON, N. (1944). A photometric adaptation of the Somogyi method for determination of glucose. Journal of Biological Chemistry 153, 375-380.
Whitney, P. J., Vaughan, J. G. \& Heale, J. B. (1968). A disc electrophoretic study of the proteins of Verticillium albo-atrum, Verticillium dahliae and Fusarium oxysporum with reference to their taxonomy. Journal of Experimental Botany 19, 415-426.

Willetts, H. J., Byrde, R. J. W., Fielding, A. H. \& Wong, A. L. (1977). The taxonomy of the brown rot fungi (Monilinia spp.) related to their extracellular cell wall-degrading enzymes. Journal of General Microbiology 103, 77-83.

Wright, G. L., JR, FARRel, V. B. \& Roberts, D. B. (1973). An evaluation of gradient acrylamide gel electrophoresis and acrylamide gel isoelectric focusing for the primary separation of complex mixtures of proteins: comparison of one- and two-dimensional analytical procedures. Biochimica et biophysica acta 295, 399-407.

WRINGLEY, C. W. (1971). Gel electrofocusing. Methods in Enzymology 22, 559-564.

ZALEWSKA-SOBCZAK, J. \& URBANEK, H. (1975). Purification of polygalacturonase produced by Botrytis cinerea E-200. Bulletin de l'Académie polonaise des sciences: Série des sciences biologiques 23, 663-668. 